\title{
Claes Ablund
}

\section{Litteraturvetenskap vid Åbo Akademi - ett ämne med många ansikten}

Ämnet litteraturvetenskap omfattar hela den "allmänna", d.v.s. västerländska litteraturen, men den forskning som bedrivits har i stor utsträckning varit inriktad på den svenskspråkiga litteraturen i Finland - och i Sverige. Områden som ägnats ett mera omfattande intresse är bl.a. finlandssvensk dramatik och lyrik, kritikhistoria, barn- och ungdomslitteratur, litteratursociologi med inriktning på opinionsbildning och propaganda samt ekokritik.

Litteraturvetenskapen vid Åbo Akademi var tidigt ute med undervisning och forskning i barn- och ungdomslitteratur. Docent Mia Österlund (universitetslärare i litteraturvetenskap) fokuserar i sin forskning på genus och normkritik. Efter avhandlingen om könsöverskridning i ungdomsromaner, Förklädda fickor (2005), övergick hon till att granska genus i nordiska bilderböcker. Genom Finlands Akademi-projektet Doing Gender in Children's Culture 2009-2010 involverades Österlund i flickforskningsnätverket Tyttötutkimusverkosto, i vars ledningsgrupp hon varit verksam, samt i forskningsnätverket Flickforsk! Nordic Network for Girlhood Studies, där hon var en av redaktörerna för antologin Flicktion. Perspekiv på fickan i fiktionen (2013). Beröringspunkterna mellan forskningen inom barn- och ungdomslitteratur och genusvetenskaplig litteraturforskning är många, vilket avspeglas i ämnets kursutbud med kurser som "Från flätor till flickmakt", som gått sedan 1990-talet i olika tappning. Flickforskningen och skildringen av flickor har överlag varit ett tyngdpunktsområde, inte bara då det gäller barn- och ungdomslitteratur utan också i satsningar på forskning om samtida författarskap som i antologin Novel Districts. Critical Readings of Monika Fagerholm (2016).

För närvarande är ämnet involverat i ett forskningsprojekt om barnlitteratur ur etnicitetssynvinkel, The Children's Library Project, finansierat av KONE-stiftelsen samt i det norska forskningsnätverket DIPI - "What difference does the picturebook make?" Pågående barnlitteraturforskning handlar därutöver bl.a. om fettstudier, kroppsstorlek och kroppspolitik i bilderböcker samt djurblivande och fågelnärvaro i bilderboken. Till Tove Janssons författarskap återkommer vi också ständigt inom ämnet, både i forskning och undervisning.

I sin doktorsavhandling Energy, Heterotopia, Dystopia (2001) analyserade FD Pia Maria Ahlbäck (universitetslärare i litteraturvetenskap) 1900-talets miljöföreställningar med utgångspunkt i George Orwells dystopiska romaner och hans journalistik. 
Avhandlingen var en av de första i Norden på forskningsfältet ekokritik. Sedan 2004 har kurser i ekokritik givits vid ämnet, och idag skriver allt fler studerande sin kandidat- eller magistersavhandling om något ekokritiskt ämne. Ahlbäck är en av initiativtagarna till det internationella nätverket Ecocritical Network in Scandinavian Studies (ENSCAN), grundat 2016, där hon också ingår i ledningsgruppen. Samtidigt har den ekokritiska forskningen en stark koppling till ett annat av ämnets forskningsintressen, utopi och dystopi, samt till forskning om barn- och ungdomslitteratur. Sommaren 2017 arrangerar litteraturvetenskapen vid $\AA$ A tillsammans med litteraturämnena vid Turun Yliopisto den internationella konferensen NorLiT, med temat Nordic Utopias and Dystopias.

Den forskning som professor Claes Ahlund på senare år bedrivit är till stor del inriktad på området ideologier, tendenslitteratur och opinionsbildning. I ett par böcker (Diktare i krig, 2007 och Underhållning och propaganda, 2010) och i åtskilliga artiklar har han behandlat den svenska litteraturens förhållande till första världskriget med särskilt fokus på dess opinionsbildande roll. Han har också lett ett internationellt mångvetenskapligt nätverk inriktat på de neutrala skandinaviska länderna under första världskriget och varit redaktör för den antologi som utgivits inom ramen för detta: Scandinavia in the First World War: Studies in the War Experience of the Northern Neutrals (2012). I ett nytt projekt under utveckling planerar han att undersöka vilka föreställningar om Finland som konstrueras och propageras i svensk press och litteratur under perioden 1809-1922.

Bland övriga forskare knutna till ämnet bör två särskilt nämnas: FD Anna MöllerSibelius och FD Freja Rudels. Anna Möller-Sibelius har efter sin bok Roll, retorik och modernitet i Bertel Gripenbergs lyrik (2015) nyligen färdigställt en monografi om dikt och ideologi i finlandssvensk lyrik under 1960- och 70-talen. Hon undersöker nu inom ramen för det internationella forskningsprojektet "The Politics of Literary History" litteraturhistorieskrivning gällande den svenska litteraturen i Finland. Rudels har efter sin doktorsavhandling om tre romaner av Per Olov Enquist nyligen inlett ett postdok-projekt om etiska strategier i den svenskspråkiga samtidsromanen. De pågående doktorandprojekten inom ämnet ansluter sig i vissa fall till de redan presenterade bredare forskningsinriktningarna, men utöver detta skrivs nu bl.a. doktorsavhandlingar om finlandssvenska författare som Karin Smirnoff, Joel Pettersson, Oscar Parland, Bo Carpelan och Eva-Stina Byggmästar. 